\title{
Chronic Headache after Pediatric Brain Injury: A Systematic Review
}

\author{
Devi E. Nampiaparampil ${ }^{1,2}$ \\ ${ }^{1}$ Interventional Pain Management Service, Department of Veterans Affairs, New York, USA \\ ${ }^{2}$ Departments of Anesthesiology \& Rehabilitation Medicine, \\ New York University School of Medicine, New York, USA \\ E-mail: devichechi@gmail.com \\ Received February 12, 2011; revised March 23, 2011; accepted April 27, 2011
}

\begin{abstract}
Introduction: Chronic pain is an under-diagnosed consequence of traumatic brain injury (TBI) in subjects aged $\leq 16$. The objective of this study was to determine its prevalence. Methods: The Ovid/Medline database was searched for articles published between 1951 and February 2008 using any combination of the terms brain injury, pain, headache, blast injury, and combat. The PubMed, MD Consult, Cochrane Collaboration, National Institutes of Health Clinical Trials Database, Meta-Register of Current Controlled Trials, and CRISP databases were searched using the keyword brain injury. 1110 articles were identified for evaluation. 258 articles were reviewed and 26 met the inclusion criteria for calculating the prevalence of chronic pain after TBI. Three cross-sectional studies met the inclusion criteria for calculating this prevalence in the population aged $\leq 16$. Results: Twenty-six studies (18 cross-sectional, 5 prospective, and 3 retrospective) including 4468 patients with TBIs were identified. Fifteen studies assessed headache (HA) pain in 1932 patients. Of these, 1081 complained of chronic HA, yielding a prevalence of $56.0 \%$ (95\% CI, 53.9\% - 58.2\%). Three studies furnished data on 262 patients with TBI and age $\leq 16$. One-hundred-fifteen of these subjects experienced chronic HA suggesting prevalence of $43.9 \%$ (95\% CI, 37.9\% - 49.9\%) in this population. We found evidence to suggest that there is an association between TBI and the development of chronic HA pain. Conclusions: Chronic pain from headache is a common complication of TBI and is common even among children with apparently minor injuries to the brain. The evidence suggests that this condition is independent of psychiatric disorders such as post-traumatic stress disorder and depression.
\end{abstract}

Keywords: Traumatic Brain Injury, Pediatrics, Pain, Headache

\section{Introduction}

The Centers for Disease Control estimates that 1.4 million individuals in the United States suffer from traumatic brain injuries (TBI) each year [1]. The diagnosis can be made in patients with a history significant for loss of consciousness, altered consciousness after head injury, or post-traumatic amnesia [2]. These head injuries can occur either when the head forcefully strikes an object, when an object penetrates the skull, or when brain tissue undergoes a sudden acceleration, deceleration, or both. In children, TBI most commonly occurs as the result of motor vehicle accidents, falls, and sports injuries [3].

Each year, TBI in all ages leads to an estimated 235,000 hospitalizations and 50,000 deaths, in addition to direct and indirect costs of $\$ 56.3$ billion [1]. After analysis of the Healthcare Cost and Utilization Project Kids' Inpatient Database, Scheier et al. found that in the year 2000 , TBI in patients $\leq 17$ years of age accounted for more than $\$ 1$ billion in hospitalization charges, making TBI one of the most costly hospital diagnoses for children [4]. The primary cause of death among Americans $<24$ years of age is brain injury from unintentional [5-7] injury. In the pediatric population, nonfatal brain injury can affect key developmental processes such as learning, emotional awareness, and social functioning [8]. Current expert opinion regarding brain injury suggests that pediatric TBI has fewer long-term consequences because of the larger measure of brain plasticity in children compared to adults. However, in the context of TBI, there is 
increasing evidence that the developing brain may have unique vulnerabilities [9]. Experimentally, there appears to be increased post-injury apoptotic cell death in the developing brains of neonatal vs. mature animals [10-13]. Clinically, studies have shown an increased risk of posttraumatic seizures in pediatric patients compared to adult patients [14-16].

Prior studies have shown that chronic pain is a potential complication of TBI [17-43]. Prior studies have shown that patients with TBI have a high prevalence of chronic pain syndromes such as headache [17-31], shoulder pain [32], heterotopic ossification [33], complex regional pain syndrome [34], and peripheral nerve injuries [35]. The association of TBI with chronic pain was first described in 1915 in troops returning from World War I with "shell shock" [44]. One study of veterans returning from Iraq and Afghanistan experiencing post-concussive syndrome found that post-traumatic stress disorder accounted for all symptoms except for pain. This suggests that the mechanism for developing chronic pain is physiologically tied to brain injury [36].

Given the morbidity associated with chronic pain and the availability of effective treatment strategies, this systematic review was initiated to determine the prevalence of chronic pain as an under-diagnosed consequence of traumatic brain injury (TBI) in subjects aged $\leq 16$.

\section{Methods}

Studies were identified that could provide information on the prevalence of chronic pain among patients who had sustained TBI. The Ovid/Medline database was searched for articles published between 1951 and February 2008 using any combination of the terms brain injury, pain, headache, blast injury, and combat. The PubMed and MD Consult databases were searched in a similar fashion for additional articles. The Cochrane Collaboration, National Institutes of Health Clinical Trials Database, MetaRegister of Current Controlled Trials, and CRISP databases were searched using the keyword brain injury.

All selected articles were published in peer-reviewed journals and contained original data on pain syndromes present after TBI with respect to prevalence, pain category, risk factors, pathogenesis, and clinical course. Manual searches were performed of the reference lists of selected articles and the authors of 2 selected studies were contacted regarding potential additional references. The search was not limited by language or publication status. No randomized controlled studies were found in the search (all patients were recruited into studies after the brain injury had occurred). Case reports and review articles were cited only if no other data were available.

The initial search yielded 1067 articles and 43 others were selected from the reference lists of retrieved articles. Of these 1110 articles, 1084 were excluded because they did not fulfill the primary inclusion criteria: the prevalence of chronic pain could not be calculated among their TBI populations. The three experts contacted for this study were not aware of any negative studies that had not been published.

The data from the final 26 studies on chronic pain after TBI were pooled by adding the results across studies. Since the studies were cross-sectional (18), prospective observational (5), or retrospective (3), none were given additional weighting. The data from the studies evaluating headache were pooled to determine the overall prevalence of headache among patients with TBI. The data from the 23 studies assessing the adult population were used in a separate analysis. The data from the 3 studies assessing pain in subjects $\leq 16$ were pooled to determine the prevalence of chronic headache in the pediatric population. Chronic headache in the pediatric population was defined headache present at $>1$ year after the initial injury.

$P$ values were derived by significance testing of two population proportions using a 2-proportion $\mathrm{z}$ test with unequal variances. The results of each individual study were compared with those of the studies combined. The prevalence rates of pain were calculated with $95 \%$ confidence intervals in each single study and in the pooled data. Analyses were performed using SAS version 9.1 (SAS Institute Inc, Cary, NC); $p<0.05$ was considered statistically significant.

\section{Results}

Twenty-six studies [17-34,36-43] (18 cross-sectional, 5 prospective, and 3 retrospective) including 4468 patients with TBIs were identified that reported on the prevalence of chronic pain after TBI. Table 1 provides a summary of the articles selected for review in the pediatric population [17-19].

\section{Headache}

Fifteen studies assessed headache (HA) pain in 1932 patients [17-31]. Among these subjects, 1081 complained of chronic HA, yielding a prevalence of $56.0 \%(95 \% \mathrm{CI}$, $53.7 \%$ - 58.2\%). Although several studies investigated pediatric TBI, only 3 studies isolated headache as an outcome measure [17-19]. These studies furnished data on 262 patients with TBI and age $\leq 16$. These 3 studies' criteria for judging chronicity was that the subjects continued to have headaches at the time that they were recruited. This time period was at least 1 year after the initial trauma.

Necajauskaite et al. conducted a cross-sectional study 
Table 1. Headache prevalence in pediatric patients with traumatic brain injury.

\begin{tabular}{|c|c|c|c|c|c|}
\hline Study & Study Design & $\begin{array}{c}\text { Total } \\
\text { Patients }\end{array}$ & $\begin{array}{l}\text { Time after } \\
\text { Event }\end{array}$ & Severity & Pain Prevalence \\
\hline $\begin{array}{l}\text { Necagauskaite et al., } \\
2005[17]\end{array}$ & Cross-sectional & 102 & $1-5$ years & Mild & $\begin{array}{l}62.7 \%(95 \% \text { CI, } 53.3 \%-72.1 \%) \text { with HA one year } \\
\text { after trauma; } 42.2 \% \text { had moderate HA; HA was present } \\
\geq 8 \text { days/month in } 43.8 \% \text { of subjects evaluated at } 1 \text { year } \\
\text { after trauma and in } 12.5 \% \text { at } 2 \text { years after trauma }\end{array}$ \\
\hline $\begin{array}{l}\text { Overweig-Plandsoen } \\
\text { et al., } 1998 \text { [18] }\end{array}$ & Cross-sectional & 22 & 3 years & Mild & $45.4 \%(95 \%$ CI, $24.6 \%$ - $66.2 \%)$ had HA \\
\hline Lanzi et al., 1985 [19] & Cross-sectional & 138 & $\begin{array}{l}12-18 \\
\text { months }\end{array}$ & $\begin{array}{l}63.7 \% \text { with } \\
\text { mild TBI }\end{array}$ & $\begin{array}{l}29.7 \%(95 \% \text { CI, } 16.1 \% \text { - } 30.2 \%) \text { with HA; } 6.5 \% \\
\text { diagnosed with migraines }\end{array}$ \\
\hline
\end{tabular}

in Lithuania investigating post-concussion syndrome in children aged 4 - 16, who had experienced a single mild TBI [17]. $72.5 \%$ of the population was male and the mean age at the time of evaluation was 11.3 for males and 9.9 for females. These 102 children were evaluated 1 - 5 years post-TBI. $70.6 \%$ of the children had headache immediately after the trauma. $62.7 \%$ experienced chronic HA. $47.1 \%$ reported headache being present prior to the trauma. Of the headache-free respondents, $51.9 \%$ developed post-traumatic headache. The authors found that in children with mild TBI, there was a significant increase in the number of headaches after the trauma $(p<0.03)$. There may have been respondent bias in the study since $62.7 \%$ of parents responded that their children had headaches within the past year. Responses of children who had sustained TBIs in the preceding $1-2$ years were compared to those of children who had had TBIs for 2 5 years. $45.3 \%$, of patients with mild TBI reported headaches that occurred 1 - 7 days per month. $43.8 \%$ of patients with mild TBIs in the past year had $\geq 8$ headaches/ month. This number decreased to $12.5 \%$ in subjects $\geq 2$ years after trauma $(p=0.01) .42 .2 \%$ of respondents had headaches of moderate severity. $40.6 \%$ had unilateral headaches of $<30$ minutes duration. $29.7 \%$ reported that the headache was triggered by irregular sleep.

Overweg-Plandsoen et al. studied the pediatric mild TBI population in the Netherlands [18]. They selected patients who met 1 of the following 3 criteria: 1) posttraumatic LOC $<20$ minutes, 2) post-traumatic amnesia $<20$ minutes, and 3) presence of at least 2 of the following symptoms: headache, nausea and vomiting, and decline of consciousness after a lucid interval. Of the 22 children who had sustained mild TBIs 2 years prior, $45.5 \%$ developed post-traumatic headache.

Lanzi et al. studied the incidence and clinical characteristics of headache in the pediatric population $12-18$ months after cranial trauma in Italy in 1985 [19]. These patients had all had injuries that necessitated hospitalization. One-hundred-thirty-eight individuals aged 3 - 17 participated in the study. The children were questioned by the examiners regarding headache symptoms in the presence of at least one parent. $29.7 \%$ of them reported chronic headache. In $6.5 \%$, the headache was migrainous in nature. The severity of the brain injury was differentiated according to the following criteria: mild = no loss of consciousness; moderate $=$ loss of consciousness; severe $=$ loss of consciousness with residual focal neurologic signs. The majority of respondents $(63.8 \%)$ had mild TBIs. The authors reported that there was no correlation between site of head injury and site of headache in $41.5 \%$ of patients. This study suggested that headache was relatively more common in patients with moderatesevere trauma. Interestingly, the study also reported that two of the pediatric patients with pre-existing diagnoses of migraines had remission of symptoms after the trauma. There is only one other study that was reviewed that discussed resolution of pain symptoms after head trauma [22].

These 3 studies [17-19] including 262 patients, provided data on the pediatric TBI population. 115 of these children reported chronic headache pain, yielding an estimated prevalence rate of $43.9 \%$ (95\% CI, 37.9\% $49.9 \%$ ). We found evidence to suggest that there is an association between TBI and the development of chronic HA pain.

This prevalence of chronic headache in this population appears to be lower than the prevalence rate of $57.8 \%$ found in a companion study of primarily adult patients [45]. This may be because pediatric and adolescent patients may have better outcome measures than adult patients. Alternatively, this difference could be due to methodological limitations with respect to recruitment bias and measurement bias.

In terms of recruitment, Necajauskaite et al. and Overweig-Plandsoen et al. selected subjects who had been seen in the emergency rooms of academic hospitals [17,18]. Lanzi et al. selected patients who had previously been hospitalized for their head injuries [19]. In their study of pediatric patients in Minnesota, Reid et al found a post-admission case fatality rate of $4.6 \%$ [46]. This was higher than the $2.5 \%$ reported by Kraus et al. for a population younger than 15 years of age [47]. The authors 
posited that this might reflect the trend towards outpatient management of mild brain injury. This suggests that the patients seen by Lanzi et al. may have had more severe brain injuries. Interestingly, their prevalence of pain (29.7\%) was lower than the prevalence found in either of the two studies: Necajauskaite (62.7\%) and OverweigPlandsoen (45.4\%). This is in line with studies in adult patients where the prevalence of chronic pain appears to be higher in those with apparently minor head trauma.

It is possible that children with more cognitive difficulties may have been unable to process or accurately respond to questions about their headaches. Both the Necajauskaite and Overweig-Plandsoen studies had investigators who questioned the parents about their children's symptoms $[17,18]$. In the Lanzi et al. study, the children were questioned directly [19]. This may also have contributed to the difference in the apparent prevalence of chronic headache.

\section{Comments}

A general limitation in measuring the incidence of post-traumatic headache in pediatric patients is in determining whether the headache is the result of trauma or whether it is a migraine or other headache syndrome that would have manifested itself over time irrespective of the head injury.

In addition, this review has specific limitations. First, all of the studies evaluating pediatric pain are cross-sectional so we do not know how symptoms may change with time. Second, it is possible that the study populations demonstrated heterogeneity in terms of cause of injury, treatment at the time of injury, recruitment procedures, and differences in and assessments of pain. The patients were selected from three different countries: Lithuania, the Netherlands, and Italy, where the epidemiology and management of TBI may be different from country to country. All of the studies utilized convenience samples rather than random samples. Third, all of the data relied on patient report, which can be biased. Fourth, most of the studies did not provide information necessary for further subgroup analyses. Future research would benefit from standardization in this regard.

Traumatic brain injury is one of the main causes of morbidity and mortality in the pediatric and adolescent population. Chronic pain may be one of the main contributors to the morbidity associated with this diagnosis. This is the first systematic review to assess the prevalence of chronic headache pain in this population. The findings suggest that more attention should be directed towards evaluating children who have history of head trauma for chronic headache.

\section{Conclusions}

Chronic pain is a common complication of TBI and contributes to morbidity as well as potentially poor recovery after TBI. Given the high prevalence of chronic headache after pediatric TBI, it may be beneficial for healthcare providers, patients, and their families to be aware of symptoms that could possibly follow the injury. This might allow for earlier treatment of pain and improved quality of life. It is also unclear what the financial impact of untreated chronic pain is in this population. Pediatric and adolescent patients may benefit from early treatment strategies to decrease the morbidity that untreated chronic pain can impose on them, their immediate caregivers, and on society. Further research is needed to characterize the nature and extent of post-traumatic pain in the pediatric population.

\section{Author Contributions}

Dr. Nampiaparampil had full access to all of the data in the study and takes responsibility for the integrity of the data and the accuracy of the data analysis.

\section{References}

[1] J. A. Langlois, W. Rutland-Brown and K. E. Thomas, "Traumatic Brain Injury in the United States: Emergency Department Visits, Hospitalizations, and Deaths," Centers for Disease Control and Prevention, National Center for Injury Prevention and Control, Atlanta, 2004.

[2] Mild Traumatic Brain Injury Committee of the Head Injury Interdisciplinary Special Interest Group of the American Congress of Rehabilitation Medicine, "The Definition of Traumatic Brain Injury," The Journal of Head Trauma Rehabilitation, Vol. 8, No. 3, 1993, pp. 86-87.

[3] H. T. Keenan and S. L. Bratton, "Epidemiology and Outcomes of Pediatric Traumatic Brain Injury," Developmental Neuroscience, Vol. 28, No. 4-5, 2006, pp. 256263. doi: $10.1159 / 000094152$

[4] A. J. Schneier, B. J. Shields, S. G. Hostetler, H. Xiang and G. A. Smith "Incidence of Pediatric Traumatic Brain Injury and Associated Hospital Resource Utilization in the United States," Pediatrics, Vol. 118, No. 2, 2006, pp. 483-492. doi: $10.1542 /$ peds.2005-2588

[5] D. Fife and J. Jagger, "The Contribution of Brain Injury to the Overall Injury Severity of Brain-Injured Patients," Journal of Neurosurgery, Vol. 60, No. 4, 1984, pp. 697 699. doi:10.3171/jns.1984.60.4.0697

[6] T. Mayer, M. L. Walker, D. G. Johnson and M. E. Matlak, "Causes of Morbidity and Mortality in Severe Pediatric Trauma," The Journal of the American Medical Association, Vol. 245, No. 7, 1981, pp. 719-721. doi:10.1001/jama.245.7.719

[7] Centers for Disease Control and Prevention, "Web-Based 
Injury Statistics Query and Reporting System," 2000. Accessed September 30, 2008.

www.cdc.gov/ncipc/wisqars/

[8] B Benz, A Ritz, S.Kiesow, "Influence of Age-Related Factors on Long-Term Outcome after Traumatic Brain Injury in Children: A Review of Recent Literature and Some Preliminary Findings," Restor Neurol Neurosci, Vol. 14, 1999, pp. 135-141.

[9] C. C. Giza, R. B. Mink and A. Madikians, "Pediatric Traumatic Brain Injury: Not Just Little Adults," Current Opinion in Critical Care, Vol. 13, No. 2, 2007, pp. 143152. doi:10.1097/MCC.0b013e32808255dc

[10] P. Bittigau, M. Sifiringer, U. Felderhoff-Mueser and C. Ikonomidou, "Apoptotic Neurodegeneration in the Context of Traumatic Injury to the Developing Brain," $E x-$ perimental and Toxicologic Pathology, Vol. 56, No. 1-2, 2004, pp. 83-89. doi:10.1016/j.etp.2004.04.006

[11] P. Bittigau, M. Sifiringer, D. Pohl, et al., "Apoptotic Neurodegeneration Following Trauma Is Markedly Enhanced in the Immature Brain," Annals of Neurology, Vol. 45, No. 6, 1999, pp. 724-735.

doi:10.1002/1531-8249(199906)45:6<724::AID-ANA6> 3.0.CO;2-P

[12] J. W. Huh, M. A. Franklin, A. G. Widing and R. Raghupathi, "Regionally Distinct Patterns of Calpain Activation and Traumatic Axonal Injury Following Contusive Brain Injury in Immature Rate," Developmental Neuroscience, Vol. 28, 2006, pp. 466-476. doi:10.1159/000094172

[13] D. Pohl, P. Bittigau, M. J. Ishimaru, et al., "N-Methyl-DAspartate Antagonists and Apoptotic Cell Death Triggered by Head Trauma in the Developing Rat Brain," Proceedings of the National Academy of Sciences of the USA, Vol. 96, 1999, pp. 2508-2513. doi:10.1073/pnas.96.5.2508

[14] J. F. Annegers, J. D. Grabow, R. V. Groover, et al., "Seizures after Head Trauma: A Population Study," Neurology, Vol. 30, 1980, pp. 683-689.

[15] I. Asikainen, M. Kaste and S. Sarna, "Early and Late Post-Traumatic Seizures in Traumatic Brain Injury Rehabilitation Patients: Brain Injury Factors Causing Late Seizures and Influence of Seizures on Long-Term Outcome," Epilepsia, Vol. 40, 1999, pp. 584-589. doi:10.1111/j.1528-1157.1999.tb05560.x

[16] A. Chiaretti, "The Management of Immediate Post-Traumatic Seizures in Children Following Minor Head Injury: Time for a Multicenter Study?" Child's Nervous System, Vol. 18, 2002, pp. 109-110. doi:10.1007/s00381-002-0561-8

[17] O. Necajauskaite, M. Endziniene and K. Jurieniene, "Prevalence, Clinical Features, and Accompanying Signs of Post-Traumatic Headache in Children," Medicina (Kaunas), Vol. 41, No. 2, 2005, pp. 100-108.

[18] W. C. G. Overweg-Plandsoen, A. Kodde, M. van Straaten, E. A. M. Van der Linden, L. G. J. Neyens, A. P. Aldenkamp and M. Vermeulen, "Mild Closed Head Injury in Children Compared to Traumatic Fractured Bone; Neurobehavioral Sequelae in Daily Life 2 years after the Ac- cident," Neuropediatrics, Vol. 158, No. 3, 1999, pp. 249 252.

[19] G. Lanzi, U. Balotti, R. Borgatti, G. De Agostini, S. Pezzotta and G. Spanu, "Late Post-Traumatic Headache in Pediatric Age," Cephalalgia, Vol. 5, No. 4, 1985, pp. 211215. doi:10.1046/j.1468-2982.1985.0504211.x

[20] D. P. Alfano, G. J. G. Asmundson, D. K. Larsen, et al., "MTBI and Chronic Pain: Preliminary Findings," $A b-$ stracts: Archives of Clinical Neuropsychology, Vol. 15, 2000, pp. 831-832.

[21] G. De Benedittis and A. De Santis, "Chronic Post-Traumatic HA: Clinical, Psychopathological Features and Outcome Determinants," Journal of Neurosurgical Sciences, Vol. 27, 1983, pp. 177-186.

[22] O. K. Jensen and F. F. Nielsen, "The Influence of Sex and Pre-Traumatic HA on the Incidence and Severity of HA after Head Injury," Cephalalgia, Vol. 10, No. 6, 1990, 285-293. doi:10.1046/j.1468-2982.1990.1006285.x

[23] S. Lahz and R. A. Bryant, "Incidence of Chronic Pain Following TBI," Archives of Physical Medicine and Rehabilitation, Vol. 77, No. 9, 1996, pp. 889-891. doi:10.1016/S0003-9993(96)90275-0

[24] P. J. B. Landy, "Neurological Sequelae of Minor Head and Neck Injuries," Injury, Vol. 29, No. 3, 1998, pp. 199206. doi:10.1016/S0020-1383(97)00178-2

[25] G. Mooney, J. Speed and S. Sheppard, "Factors Related to Recovery after mTBI," Brain Injury, Vol. 19, No. 12, 2005, pp. 975-987. doi:10.1080/02699050500110264

[26] M. C. Ouellet, S. Beaulieu-Bonneau and C. M. Morin, "Insomnia in Patients with TBI: Frequency, Characteristics, and Risk Factors," Journal of Head Trauma Rehabilitation, Vol. 21, No. 3, 2006, pp. 199-212. doi:10.1097/00001199-200605000-00001

[27] R. W. Rimel, B. Giordani, J. T. Barth, et al., "Disability Caused by Minor Head Injury," Neurosurgery, Vol. 9, No. 3, 1981, pp. 221-228. doi:10.1227/00006123-198109000-00001

[28] W. F. Schaller, "After-Effects of Head Injury," Journal of the American Medical Association, Vol. 113, No. 20, 1939, pp. 1779-1785.

[29] L. Smith-Seemiller, N. R. Fow, R. Kant, et al., "Presence of Post-Concussion Syndrome Symptoms in Patients with Chronic Pain vs. mTBI," Brain Injury, Vol. 17, No. 3, 2003, pp. 199-206.

[30] J. M. Uomoto and P. C. Esselman, "TBI and Chronic Pain: Differential Types and Rates by Head Injury Severity," Archives of Physical Medicine and Rehabilitation, Vol. 74, No. 1, 1993, pp. 61-64.

[31] M. Yamaguchi, "Incidence of HA and Severity of Head Injury," HA, Vol. 32, No. 9, 1992, pp. 427-431.

[32] J. Leung, A. Moseley, S. Fereday, et al., "The Prevalence and Characteristics of Shoulder Pain after TBI," Clinical Rehabilitation, Vol. 21, 2007, pp. 171-191. doi:10.1177/0269215506070254

[33] D. E. Garland, C. E. Blum and R. L. Waters, "Periarticular Heterotopic Ossification in Head-Injured Adults. In- 
cidence and Location," Journal of Bone \& Joint Surgery Vol. 62, No. 7, 1980, pp. 1143-1146.

[34] H. Gellman, M. E. Keenan, L. Stone, et al., "Reflex Sympathetic Dystrophy in Brain-Injured Patients," Pain, Vol. 51, No. 3, 1992, pp. 307-11. doi:10.1016/0304-3959(92)90214-V

[35] J. L. Cosgrove, M. Vargo and M. E. Reidy, "A Prospective Study of Peripheral Nerve Lesions Occurring in Traumatic Brain-Injured Patients," American Journal of Physical Medicine \& Rehabilitation, Vol. 68, No. 1, 1989, pp. 15-17. doi:10.1097/00002060-198902000-00005

[36] C. W. Hoge, D. McGurk, J. L. Thomas, et al., "Mild Traumatic Brain Injury in U.S. Soldiers Returning from Iraq," The New England Journal of Medicine, Vol. 358, No. 5, 2008, pp. 453-463. doi:10.1056/NEJMoa072972

[37] J. M. Hoffman, K. F. Pagulayan, N. Zawaideh, et al., "Understanding Pain after TBI: Impact on Community Participation," American Journal of Physical Medicine \& Rehabilitation, Vol. 86, 2007, pp. 962-969. doi:10.1097/PHM.0b013e31815b5ee5

[38] R. A. Bryant, J. E. Marosszeky, J. Crooks, et al., "Interaction of Posttraumatic Stress Disorder and Chronic Pain Following TBI," The Journal of Head Trauma Rehabilitation, Vol. 14, No. 6, 1999, pp. 588-594. doi:10.1097/00001199-199912000-00007

[39] D. P. Alfano, "Emotional and Pain-Related Factors in Neuropsychological Assessment Following mTBI," Abstracts: Brain and Cognition, Vol. 60, No. 2, 2006, pp. 193-217.

[40] J. T. Beetar, T. J. Guilmette and F. R. Sparadeo, "Sleep and Pain Complaints in Symptomatic Tbi and Neurologic Populations," Archives of Physical Medicine and Reha- bilitation, Vol. 77, No. 12, 1996, pp. 1298-1302.

[41] J. H. Olver, J. L. Ponsford and C. A. Curran, "Outcome Following TBI: A Comparison between 2 and 5 Years after Injury," Brain Injury, Vol. 10, No. 11, 1996, pp. 841848. doi:10.1080/026990596123945

[42] W. C. Walker, R. T. Seel, G. Curtiss and D. L. Warden, "HA after Moderate and Severe TBI: A Longitudinal Analysis," Archives of Physical Medicine and Rehabilitation, Vol. 86, No. 9, 2005, pp. 1793-1800. doi:10.1016/j.apmr.2004.12.042

[43] D. L. Warden, L. M. Ryan, K. M. Helmick, et al., "War Neurotrauma: The Defense and Veterans Brain Injury Center (DVBIC) Experience at Walter Reed Army Medical Center (WRAMC) Abstract," Journal of Neurotrauma, Vol. 22, No. 10, 2005, p. 1178.

[44] C. S. Myers, "A Contribution to the Study of Shellshock: Being an Account of the Cases of Loss of Memory, Vision, Smell, and Taste Admitted to the Duchess of Westminister's War Hospital, le Touquet," Lancet, Vol. 1, 1915, pp. 316-320. doi:10.1016/S0140-6736(00)52916-X

[45] D. E. Nampiaparampil, "Prevalence of Chronic Pain After Traumatic Brain Injury: A Systematic Review," The Journal of the American Medical Association, Vol. 300, No. 6, 2008, pp. 711-719. doi: $10.1001 /$ jama.300.6.711

[46] S. R. Reid, J. S. Roesler, A. M. Gaichas and A. K. Tsai, "The Epidemiology of Pediatric Traumatic Brain Injury in Minnesota," Archives of Pediatrics \& Adolescent Medicine, Vol. 155, No. 7, 2001, pp. 784-786.

[47] J. F. Kraus, A. Rock and P. Hemyari, "Brain injuries among Infants, Children, Adolescents, and Young Adults," American Jewelry Design Council, Vol. 144, No. 6, 1990, pp. 684-691. 